\title{
Primary Nonadherence to Oral Anticoagulants in Patients with Atrial Fibrillation: Real-World Data from a Population-Based Cohort
}

\author{
Clara L. Rodriguez-Bernal, PhD; Salvador Peiró, PhD; Isabel Hurtado, PhD; \\ Aníbal García-Sempere, MSc; and Gabriel Sanfélix-Gimeno, PhD
}

\begin{abstract}
BACKGROUND: Primary nonadherence (not filling a first prescription) is an important yet unstudied aspect of adherence to oral anticoagulant (OAC) therapy.

OBJECTIVE: To estimate the rates of primary nonadherence to OACs and determine associated factors in real-world practice.

METHODS: This population-based retrospective cohort study set in the Valencia region of Spain (about 5 million inhabitants) included all patients with atrial fibrillation who were newly prescribed OACs during 2011-2014 $(\mathrm{N}=18,715)$. Primary nonadherence was obtained by linking electronic prescription and dispensing data and assessed by type of OAC-vitamin $\mathrm{K}$ antagonists (VKAs) or non-VKA oral anticoagulants (NOACs). Covariates were obtained from diverse databases, including electronic medical records. Multivariate logistic regression models were used to assess characteristics associated with primary nonadherence, adjusting for a propensity score to minimize confounding by indication.

RESULTS: Primary nonadherence to OACs was $5.62 \%$ (VKA $4.29 \%$ vs. NOAC $10.81 \% ; P<0.001$ ), with varying rates among specific drugs (acenocoumarol $4.2 \%$, warfarin $10.9 \%$, apixaban $5.0 \%$, dabigatran $7.9 \%$, and rivaroxaban $15.5 \%$ ). After adjusting for potential confounders, the likelihood of not filling the first prescription was higher for NOAC patients than for VKA patients $(\mathrm{OR}=2.76,95 \% \mathrm{Cl}=2.41-3.15)$. High coinsurance in the older groups $(\mathrm{OR}=2.63,95 \% \mathrm{Cl}=1.47-4.69$ for patients aged $66-75$ years and $\mathrm{OR}=3.02,95 \% \mathrm{Cl}=1.58-5.76$ for patients aged $>75$ years); being a non-Spanish European $(\mathrm{OR}=1.49,95 \% \mathrm{Cl}=1.12-1.99)$; and having dementia $(\mathrm{OR}=1.72,95 \% \mathrm{Cl}=1.37-2.16)$ were positively associated with primary nonadherence. Electronic transmission of prescriptions $(\mathrm{OR}=0.85,95 \%$ $\mathrm{Cl}=0.74-0.96)$; liver disease $(\mathrm{OR}=0.73,95 \% \mathrm{Cl}=0.54-0.99)$; and polypharmacy $(0 R=0.59,95 \% \mathrm{Cl}=0.50-0.70)$ were inversely associated with primary nonadherence.
\end{abstract}

CONCLUSIONS: Overall, primary nonadherence to OACs was relatively low (5\%). However, important differences were found between VKAs and NOACs. After adjustment, patients prescribed NOACs nearly tripled the likelihood of nonadherence compared with patients prescribed VKAs, which could negatively affect their effectiveness in clinical practice. Identified correlates were similar to those shown in the limited evidence for other medications.

J Manag Care Spec Pharm. 2018;24(5):440-48

Copyright $\odot 2018$, Academy of Managed Care Pharmacy. All rights reserved.

\section{What is already known about this subject}

Non-VKA oral anticoagulants (NOACs) are increasingly being used over vitamin $\mathrm{K}$ antagonists (VKAs) for stroke prevention by patients with atrial fibrillation.

Real-world data show that long-term adherence and persistence to OACs are generally a problem but seem to be more pronounced with VKAs.

Primary nonadherence rates vary between 5\% and nearly 30\% for medications that treat various chronic conditions; however, primary nonadherence to $\mathrm{OAC}$ therapy in routine clinical practice has not been studied to date.

\section{What this study adds}

In this real-world study, primary nonadherence to OACs was relatively low overall (5\%), but important differences were found between VKAs and NOACs (4.3\% vs. 10.8\%, $P<0.001$ ).

Primary nonadherence rates varied between NOAC drugs, ranging from 5\% (apixaban) to $16 \%$ (rivaroxaban).

When assessing type of OAC after adjusting for potential confounders, NOAC patients showed 3-fold higher odds of nonadherence compared with VKA patients, which could negatively affect NOAC effectiveness in clinical practice.
A dherence to medication is a key factor in the effective prevention and treatment of chronic conditions. ${ }^{1-3}$ When used adequately, oral anticoagulants (OACs) substantially reduce the incidence of cardioembolic stroke in patients with atrial fibrillation (AF). ${ }^{4-8}$ Vitamin $\mathrm{K}$ antagonists (VKAs), the cornerstone therapy for years, ${ }^{9,10}$ and more recently non-VKA oral anticoagulants (NOACs), comparable in efficacy and safety to VKA in clinical trials, ${ }^{11-13}$ are used for thromboembolic risk reduction, with an important increase in NOAC prescriptions in recent years. ${ }^{14,15}$ Recent evidence regarding anticoagulant therapy in routine clinical practice indicates that long-term adherence and persistence are generally a problem, but seem to be more pronounced with VKAs, although they are not negligible in the case of NOACs. ${ }^{16-19}$

In addition to suboptimal long-term adherence, primary nonadherence, defined as the failure to fill or obtain a newly prescribed medication, ${ }^{20}$ also constitutes a serious problem for 


\section{FIGURE 1 Study Attrition with Inclusion and Exclusion Criteria}

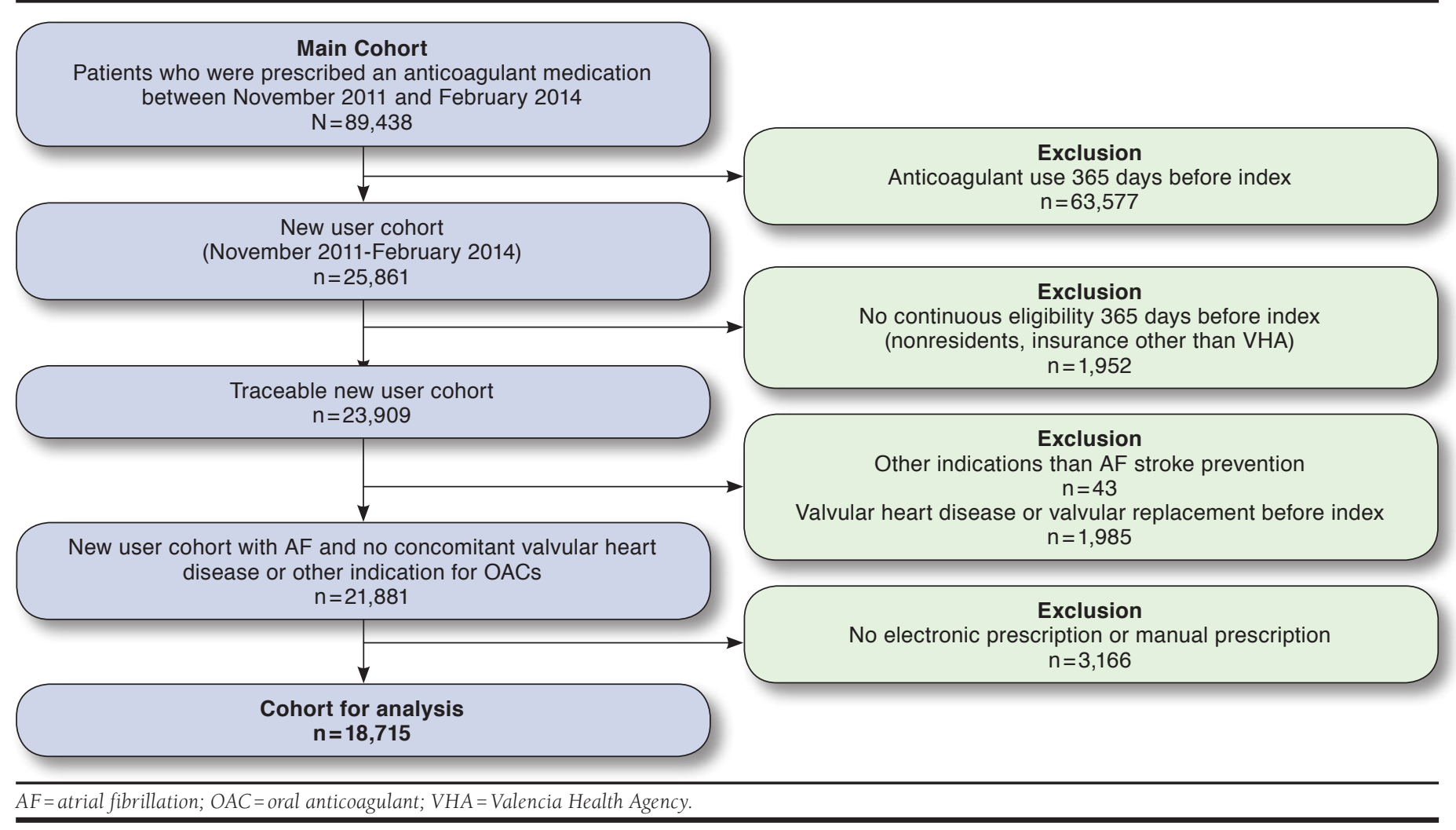

health care systems. Primary nonadherence has been shown to predict health outcomes. ${ }^{21}$ The advent of electronic prescribing has made it possible to evaluate primary nonadherence, and recent studies have found that primary nonadherence rates vary between $5 \%$ and nearly $30 \%$ for medications that treat various chronic conditions. ${ }^{20,22-26}$ Nevertheless, primary nonadherence for OACs using population-based real-world data has not been studied to date, to the best of our knowledge.

Electronic prescribing systems provide a record of prescriptions that have been issued to patients, allowing access to all prescription data, even if patients do not fill their prescriptions. ${ }^{27,28}$ Electronic dispensing systems record prescriptions that were filled at a pharmacy (i.e., picked up by patients), including those that were manually issued. The linkage of all electronic prescriptions and dispensings through a unique identifier provided by both systems without the need of algorithms or assumptions (e.g., matching of e-prescriptions and filled claims by generic or brand name within a certain period of time after the prescriptions were issued), as is the case in our population, provides an opportunity to assess primary nonadherence and its predictors more precisely and to better understand the effect of primary nonadherence on the whole issue of medication adherence.
Ultimately, this study seeks to provide evidence for physicians to make informed decisions on OAC prescription. It also aims to facilitate the development and implementation of early interventions or policies seeking to improve the management of patients initiating treatment with oral anticoagulants.

We sought to estimate the rates of primary nonadherence for VKA and NOAC therapies in real-world practice and to determine the factors associated with a higher risk of primary nonadherence.

\section{Methods}

\section{Study Design}

A population-based retrospective cohort study was conducted with all AF patients who were prescribed OAC therapy from November 2011 (marketing date of the first NOAC) to February 2014 in the Valencia region of Spain.

\section{Population and Setting}

This study focused on the population covered by the Valencia Health Agency (VHA), which is the public service responsible for health care in this region of Spain, providing universal coverage and receiving tax-based funding. An extensive network of hospitals and primary health care centers is operated by the 
VHA and shares an electronic medical record and advanced electronic prescription system that includes the ability to trace prescriptions (from the prescription by the physician to the dispensing of the drug in pharmacies and subsequent claims to the VHA). A unique identifier is used to link the prescriptions with dispensings, requiring no further follow-up for determining primary nonadherence.

In Valencia, all community pharmacies are privately owned and can only be owned by pharmacists. Chains are banned, and the establishment of new pharmacies is controlled by the government based on population per pharmacy and distance from other existing pharmacies. The VHA covers about $97 \%$ of the region's population (about 5 million inhabitants).

All patients with AF (International Classification of Diseases, Ninth Revision, Clinical Modification [ICD-9-CM] diagnosis code 427.31) and prescribed OACs (warfarin, acenocoumarol, dabigatran, rivaroxaban, and apixaban) from November 2011 to February 2014 were included. A 1-year look-back period was used to define the baseline characteristics of the population. Patients without anticoagulant treatment in the 12 months before the index prescription were considered naive.

Patients were excluded because of follow-up limitations if they did not have VHA pharmaceutical/health coverage (e.g., government employees whose prescriptions are reimbursed by civil service insurance companies so would not be included in the VHA pharmacy database) or were not registered in the municipal census (nonresidents or temporary residents). Patients were also excluded if they had other indications than AF for stroke prevention and concomitant valvular heart disease (ICD-9-CM codes 394.x-397.x, 398.9, 42.4x, V42.2, V43.3, $35.1 \mathrm{x}$, and $35.2 \mathrm{x}$ ). In addition, patients were excluded if they did not have an electronic prescription because of the inability to establish a prescription-dispensing link for those prescriptions issued manually. After these exclusions, 18,715 patients were left for inclusion in this study (Figure 1).

The study protocol was approved by the Clinical Research Ethics Committee of the Dirección General de Salud Pública y Centro Superior de Investigación en Salud Públic and reviewed and classified by the Spanish Drug Agency. Data were sent by the VHA to researchers with dissociate nontraceable codes that would not allow the identification of individual patients. Exemption from informed consent was approved by the Ethics Committee considering the characteristics of the study.

\section{Data Sources}

The main source of study data was the VHA ambulatory electronic medical record (EMR), which includes demographic, clinical data, and prescription and dispensing information. Hospitalization information was obtained from the Minimum Basic Dataset (MBDS), which provides clinical and administrative information on all hospital discharges, including diagnoses and procedures. Mortality, VHA coverage, and some demographic characteristics were obtained from the Population
Information System. A detailed description of data sources can be found elsewhere. ${ }^{29}$

\section{Covariates}

Patient sociodemographic information and a wide range of data on comorbidities and health care utilization were used. Sociodemographic data included age, sex, country of origin, and pharmaceutical cost sharing. In the Spanish National Health System, pharmaceutical coinsurance (percentage of the price of the drug that has to be paid by the patient) is either $0 \%$ or $10 \%$ for pensioners (those in the population aged over 65 years) and $40 \%$ or $50 \%$ for the working population (rising to $60 \%$ for very high-income individuals), so 2 categories of cost sharing were defined: low coinsurance (0\%-10\%) and high coinsurance (40\%-60\%). Information on baseline comorbidities was obtained by taking into account the 365 days before the index date (date of the initial OAC prescription).

The following covariates were considered: congestive heart failure, hypertension, diabetes, liver and kidney disease, previous ischemic stroke or transient ischemic attack, coronary artery disease, deep vein thromboembolism or pulmonary embolism, hemorrhagic stroke, gastrointestinal bleeding, other major bleeding and history of or predisposition to bleeding, malignancy, depression, and dementia. All diagnoses were defined using ICD-9-CM codes (see Appendix, available in online article). We used active diagnoses from the EMR and primary or secondary diagnoses used during hospitalization episodes. Major bleeding risk was calculated based on HASBLED scores and the risk of thromboembolic events was based on $\mathrm{CHADS}_{2}$ or $\mathrm{CHA}_{2} \mathrm{DS}_{2}$-VASc scores. ${ }^{30-32}$

Health care utilization indicators in the previous year were the number of prescribed medications; hospitalizations; emergency department visits; visits to ambulatory care (cardiologists, neurologists, and family physician); and social worker and mental health services. Hospitalizations 30 days before treatment initiation were also considered. In addition, information was included regarding how electronic prescriptions were provided to patients (e.g., whether they were printed and given to patients or transmitted electronically to the pharmacy).

\section{Statistical Analysis}

Cohort characteristics (means for continuous variables and frequencies for categorical variables) were classified according to type of OAC prescribed. Bivariate analysis relating primary nonadherence to all baseline characteristics, including the type of anticoagulant prescribed, was performed using chi-square tests. A propensity score was calculated based on logistic regression that estimated the probability of a NOAC prescription versus a VKA prescription based on the covariates previously listed, in order to minimize indication bias. ${ }^{33}$ Subsequently, logistic multivariable regression models were 


\begin{tabular}{|c|c|c|c|}
\hline \multicolumn{4}{|c|}{ 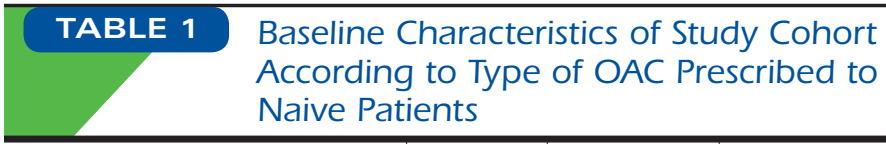 } \\
\hline & All & VKA & NOAC \\
\hline \multicolumn{4}{|l|}{ Sociodemographics } \\
\hline $\mathrm{N}(\%)$ & 18,715 & $14,913(79.7)$ & $3,802(20.3)$ \\
\hline Female (\%) & 47.7 & 47.7 & 47.4 \\
\hline Age, years, mean (SD) & $74.5(10.1)$ & $74.6 \quad(9.9)$ & $74.2(11.1)$ \\
\hline \multicolumn{4}{|l|}{ Country } \\
\hline Spain & 96.2 & 96.2 & 96.2 \\
\hline European & 3.6 & 3.6 & 3.7 \\
\hline Non-European & 0.2 & 0.2 & 0.2 \\
\hline \multicolumn{4}{|l|}{ Coinsurance $^{\mathrm{a}}$} \\
\hline Low $(0 \%-10 \%)$ & 91.3 & 92.0 & 88.5 \\
\hline High $(40 \%-60 \%)$ & 8.7 & 8.0 & 11.5 \\
\hline \multicolumn{4}{|l|}{ Prescription transmission method } \\
\hline Printed & 40.7 & 41.4 & 37.7 \\
\hline Electronic & 59.3 & 58.6 & 62.3 \\
\hline \multicolumn{4}{|l|}{ Comorbidities, \% } \\
\hline Congestive heart failure & 21.3 & 22.0 & 18.3 \\
\hline Hypertension & 79.3 & 79.7 & 77.7 \\
\hline Diabetes & 30.9 & 31.7 & 27.4 \\
\hline Liver disease & 6.2 & 6.4 & 5.6 \\
\hline Renal disease & 11.8 & 12.5 & 8.2 \\
\hline Previous ischemic stroke or TIA & 14.5 & 13.9 & 16.8 \\
\hline Coronary artery disease & 20.9 & 21.2 & 19.9 \\
\hline $\begin{array}{l}\text { Deep vein thromboembolism } \\
\text { or pulmonary embolism }\end{array}$ & 6.1 & 6.5 & 4.3 \\
\hline Hemorrhagic stroke & 0.8 & 0.7 & 1.4 \\
\hline Gastrointestinal bleeding & 3.7 & 3.7 & 3.5 \\
\hline Other major bleeding & 20.6 & 20.8 & 19.5 \\
\hline $\begin{array}{l}\text { Bleeding history or } \\
\text { predisposition }\end{array}$ & 23.2 & 23.3 & 22.5 \\
\hline $\mathrm{CHADS}_{2}$ score, mean (SD) & $2.2(1.2)$ & $2.2 \quad(1.3)$ & $2.1 \quad(1.3)$ \\
\hline $\mathrm{CHA}_{2} \mathrm{DS}_{2}$-VASC score, mean (SD) & $3.8(1.7)$ & $3.9 \quad(1.7)$ & $3.7 \quad(1.8)$ \\
\hline HAS-BLED score, mean (SD) & $2.2(1.0)$ & $2.2(1.0)$ & $2.2 \quad(1.0)$ \\
\hline Malignancy & 16.0 & 16.1 & 15.7 \\
\hline Depression & 13.0 & 12.8 & 13.6 \\
\hline Dementia & 6.9 & 6.6 & 8.1 \\
\hline \multicolumn{4}{|l|}{ Health care utilization, mean (SD)b } \\
\hline $\begin{array}{l}\text { Number of prescribed } \\
\text { medications }{ }^{\mathrm{C}}\end{array}$ & 9.9 (4.8) & $9.9 \quad(4.8)$ & $9.6 \quad(4.7)$ \\
\hline Hospitalizations & $0.7 \quad(0.9)$ & $0.7 \quad(0.9)$ & $0.6 \quad(0.9)$ \\
\hline Emergency department visits & $1.2(1.5)$ & $1.2(1.5)$ & $1.1 \quad(1.5)$ \\
\hline \multicolumn{4}{|l|}{ Ambulatory visits } \\
\hline Cardiologist visits & $0.5(0.8)$ & $0.4 \quad(0.8)$ & $0.7 \quad(0.9)$ \\
\hline Neurologist visits & $0.1 \quad(0.5)$ & $0.1 \quad(0.5)$ & $0.2(0.6)$ \\
\hline Family physician visits & $10.4(7.3)$ & $10.4 \quad(7.2)$ & $10.3(7.7)$ \\
\hline Social work visits & $0.10 \quad(0.7)$ & $0.1 \quad(0.7)$ & $0.1 \quad(0.7)$ \\
\hline Mental health visits & $0.1 \quad(0.8)$ & $0.1 \quad(0.8)$ & $0.1 \quad(0.9)$ \\
\hline $\begin{array}{l}\text { Hospitalization } 30 \text { days before } \\
\text { treatment initiation (yes) \% }\end{array}$ & 30.8 & 31.4 & 28.1 \\
\hline \multicolumn{4}{|c|}{$\begin{array}{l}\text { aCoinsurance is expressed as a percentage of the total cost of prescriptions to be paid. } \\
\text { ber year unless otherwise stated. } \\
\text { cPer month in the last year. } \\
\text { NOAC=non-VKA oral anticoagulant; OAC=oral anticoagulant; TIA=transient } \\
\text { ischemic attack; VKA = vitamin K antagonist; SD = standard deviation. }\end{array}$} \\
\hline
\end{tabular}

used to assess the independent associations between primary nonadherence and all baseline covariates (including type of OAC), with adjustment by propensity score (included in the model as a continuous covariate). An interaction term was also included between age and coinsurance, given that eligibility for type of coinsurance depends mainly on age and income. Goodness-of-fit was evaluated using the c-statistic (the area below the receiver operating characteristic curve) for discrimination and the Hoshmer-Lemeshow test for calibration. All analyses were performed by using Stata software, version 14.0 (StataCorp, College Station, TX)

\section{Results}

The baseline characteristics of the whole study population and by OAC type are shown in Table 1 . Among the 18,715 patients included, $14,913(79.7 \%)$ were prescribed VKAs, and 3,802 (20.3\%) were prescribed NOACs during the study period. Among the latter, 278 patients were prescribed apixaban; 1,982 were prescribed dabigatran; and 1,542 were prescribed rivaroxaban. The mean age of the cohort was 74.5 years, with $47 \%$ females. Over $96 \%$ of patients were born in Spain, and $8.7 \%$ had high coinsurance ( $40 \%-60 \%$ vs. $0 \%-10 \%$ of prescription cost). The most prevalent comorbidities were hypertension $(79.4 \%)$, diabetes (30.9\%), history of or predisposition for bleeding (23.2\%), congestive heart failure (21.3\%), and coronary artery disease (21.0\%). Mean scores for $\mathrm{CHADS}_{2}$, $\mathrm{CHA}_{2} \mathrm{DS}_{2}$-VASC, and HAS-BLED were 2.18, 3.85, and 2.23, respectively. Overall, NOAC initiators were more likely to have high coinsurance, less comorbidity, and lower health care utilization but showed higher rates of previous ischemic stroke or transient ischemic attack and more cardiology, neurology, and mental health visits compared with those patients who were newly prescribed VKAs.

\section{Overall Primary Nonadherence by Type of OAC}

Primary nonadherence was 5.6\% (VKAs 4.3\%, 95\% CI $=4.0$ 4.6 vs. NOACs $10.8 \%, 95 \% \mathrm{CI}=9.9-11.8 ; P<0.001$ ), with differences among specific drugs (acenocoumarol 4.2\%, 95\% $\mathrm{CI}=3.9-4.5$; warfarin $10.9 \%, 95 \% \mathrm{CI}=7.1-16.6$; apixaban $5.0 \%$, 95\% CI=3.0-8.3; dabigatran 7.9\%, 95\% CI=6.9-9.2; rivaroxaban $15.5 \%, 95 \% \mathrm{CI}=13.8-17.4 ; \mathrm{P}<0.001)$.

Table 2 shows data on primary nonadherence according to the type of OAC and baseline characteristics. Overall, younger patients (aged $\leq 65$ years), non-Spanish (and, remarkably, non-European), those with high coinsurance, and those with the lowest risk scores and dementia showed poorer primary adherence. Patients with liver or kidney disease, previous bleeding (except gastrointestinal bleeding), at least 1 visit to the cardiologist, and polypharmacy showed lower primary nonadherence. When assessing primary nonadherence according to baseline characteristics by VKAs and NOACs, similar patterns were observed. 
Primary Nonadherence to Oral Anticoagulants in Patients with Atrial Fibrillation: Real-World Data from a Population-Based Cohort

TABLE 2 Percentage of Primary Nonadherence According to Type of OAC and Baseline Characteristics

\begin{tabular}{|c|c|c|c|c|c|c|}
\hline & \multicolumn{2}{|c|}{ All, $\mathrm{N}=18,715$} & \multicolumn{2}{|c|}{ VKA, $n=14,913$} & \multicolumn{2}{|c|}{ NOAC, $n=3,802$} \\
\hline & $\%$ & $P$ Value & $\%$ & $P$ Value ${ }^{a}$ & $\%$ & $P$ Value ${ }^{a}$ \\
\hline Whole cohort & 5.6 & & 4.3 & & 10.8 & \\
\hline \multicolumn{7}{|l|}{ Sociodemographics } \\
\hline Female & 5.4 & 0.256 & 4.1 & 0.279 & 10.6 & 0.683 \\
\hline \multicolumn{7}{|l|}{ Age, years } \\
\hline$\leq 65$ & 6.5 & 0.006 & 4.9 & 0.054 & 11.9 & 0.345 \\
\hline $66-75$ & 4.9 & & 3.8 & & 9.8 & \\
\hline$\geq 76$ & 5.7 & & 4.4 & & 11.0 & \\
\hline \multicolumn{7}{|l|}{ Country } \\
\hline Spain & 5.5 & $\leq 0.001$ & 4.2 & $\leq 0.001$ & 10.4 & $\leq 0.001$ \\
\hline European & 9.2 & & 6.2 & & 20.9 & \\
\hline Non-European & 16.3 & & 16.7 & & 14.3 & \\
\hline \multicolumn{7}{|l|}{ Coinsurance $^{b}$} \\
\hline Low $(0 \%-10 \%)$ & 5.3 & $\leq 0.001$ & 4.1 & $\leq 0.001$ & 10.3 & 0.039 \\
\hline High $(40 \%-60 \%)$ & 8.5 & & 6.4 & & 14.3 & \\
\hline \multicolumn{7}{|l|}{ Prescription transmission method } \\
\hline Printed & 6.1 & 0.022 & 4.8 & 0.009 & 11.6 & 0.241 \\
\hline Electronic & 5.3 & & 3.9 & & 10.4 & \\
\hline \multicolumn{7}{|l|}{ Comorbidities } \\
\hline Congestive heart failure & 5.5 & 0.745 & 4.1 & 0.515 & 12.3 & 0.150 \\
\hline Hypertension & 5.5 & 0.156 & 4.3 & 0.946 & 10.4 & 0.109 \\
\hline Diabetes & 5.6 & 0.822 & 4.3 & 0.909 & 11.2 & 0.646 \\
\hline Liver disease & 4.1 & 0.016 & 2.9 & 0.026 & 9.4 & 0.478 \\
\hline Renal disease & 4.7 & 0.044 & 3.7 & 0.192 & 10.4 & 0.826 \\
\hline Previous ischemic stroke or TIA & 6.1 & 0.188 & 4.7 & 0.310 & 10.9 & 0.969 \\
\hline Coronary artery disease & 5.6 & 0.937 & 4.4 & 0.655 & 10.7 & 0.936 \\
\hline Deep vein thromboembolism or pulmonary embolism & 6.4 & 0.249 & 4.3 & 0.993 & 18.8 & 0.001 \\
\hline Hemorrhagic stroke & 7.2 & 0.396 & 7.8 & 0.076 & 5.9 & 0.254 \\
\hline Gastrointestinal bleeding & 4.7 & 0.286 & 4.3 & 0.718 & 7.7 & 0.244 \\
\hline Other major bleeding & 4.9 & 0.038 & 4.0 & 0.318 & 9.0 & 0.077 \\
\hline Bleeding history or predisposition & 4.9 & 0.031 & 4.0 & 0.385 & 8.8 & 0.029 \\
\hline \multicolumn{7}{|l|}{$\mathrm{CHADS}_{2}$ score } \\
\hline 0 & 7.2 & 0.003 & 5.2 & 0.046 & 13.0 & 0.155 \\
\hline 1 & 4.9 & & 3.6 & & 9.5 & \\
\hline$\geq 2$ & 5.7 & & 4.4 & & 11.0 & \\
\hline \multicolumn{7}{|l|}{$\mathrm{CHA}_{2} \mathrm{DS}_{2}$-VASC score } \\
\hline 0 & 7.8 & 0.039 & 6.1 & 0.263 & 11.5 & 0.497 \\
\hline 1 & 6.5 & & 4.5 & & 12.9 & \\
\hline$\geq 2$ & 5.5 & & 4.2 & & 10.6 & \\
\hline \multicolumn{7}{|l|}{ HAS-BLED score } \\
\hline 0 & 7.9 & 0.005 & 5.3 & 0.236 & 15.3 & 0.099 \\
\hline 1 & 6.1 & & 4.7 & & 11.1 & \\
\hline$\geq 2$ & 5.4 & & 4.2 & & 10.4 & \\
\hline Malignancy & 5.3 & 0.372 & 4.0 & 0.439 & 10.4 & 0.727 \\
\hline Depression & 5.2 & 0.385 & 3.7 & 0.148 & 11.1 & 0.839 \\
\hline Dementia & 8.8 & $\leq 0.001$ & 6.9 & $\leq 0.001$ & 14.7 & 0.024 \\
\hline \multicolumn{7}{|l|}{ Health care utilization } \\
\hline Polypharmacy ( $\geq 6$ prescribed medications) & 5.0 & $\leq 0.001$ & 3.7 & $\leq 0.001$ & 10.1 & 0.007 \\
\hline Hospitalizations (any) & 5.5 & 0.687 & 4.2 & 0.716 & 11.1 & 0.611 \\
\hline Emergency department visits (any) & 5.5 & 0.345 & 4.2 & 0.538 & 11.2 & 0.414 \\
\hline Cardiologist visits (any) & 5.1 & 0.021 & 3.7 & 0.009 & 9.1 & 0.002 \\
\hline Neurologist visits (any) & 5.8 & 0.691 & 4.9 & 0.275 & 8.9 & 0.172 \\
\hline Social work visits (any) & 7.0 & 0.082 & 5.5 & 0.137 & 13.6 & 0.266 \\
\hline Mental health visits (any) & 6.9 & 0.189 & 4.7 & 0.655 & 14.3 & 0.215 \\
\hline Hospitalization in 30 days before treatment initiation (any) & 5.4 & 0.364 & 4.1 & 0.441 & 11.1 & 0.735 \\
\hline
\end{tabular}




\begin{tabular}{|c|c|c|c|}
\hline $\begin{array}{l}\text { Factors Asso } \\
\text { Nonadherer } \\
\text { Logistic Reg }\end{array}$ & \multicolumn{3}{|c|}{$\begin{array}{l}\text { Factors Associated with Primary } \\
\text { Nonadherence to OACs: Multivariable } \\
\text { Logistic Regression Analysis }\end{array}$} \\
\hline & OR & $95 \% \mathrm{CI}$ & $P$ Value \\
\hline \multicolumn{4}{|l|}{ Type of OAC prescribed } \\
\hline NOAC (reference VKA) & 2.76 & $2.41-3.15$ & $\leq 0.001$ \\
\hline \multicolumn{4}{|l|}{ Sociodemographics } \\
\hline \multicolumn{4}{|l|}{ Country (reference Spain) } \\
\hline European & 1.49 & $1.12-1.99$ & 0.005 \\
\hline Non-European & 1.89 & $0.81-4.45$ & 0.141 \\
\hline \multicolumn{4}{|l|}{ Coinsurance age b,c } \\
\hline $66-75$ years & 2.63 & $1.47-4.69$ & $\leq 0.001$ \\
\hline $75+$ years & 3.02 & $1.58-5.76$ & $\leq 0.001$ \\
\hline $\begin{array}{l}\text { Electronic transmission of the } \\
\text { prescription (vs. printed) }\end{array}$ & 0.85 & $0.74-0.96$ & 0.012 \\
\hline \multicolumn{4}{|l|}{ Comorbidities } \\
\hline Liver disease & 0.73 & $0.54-0.99$ & 0.044 \\
\hline Dementia & 1.72 & $1.37-2.16$ & $\leq 0.001$ \\
\hline \multicolumn{4}{|l|}{ Health care utilization } \\
\hline $\begin{array}{l}\text { Polypharmacy (ref: }<6 \text { concomitant } \\
\text { medications) }\end{array}$ & 0.59 & $0.50-0.70$ & $\leq 0.001$ \\
\hline \multicolumn{4}{|c|}{ 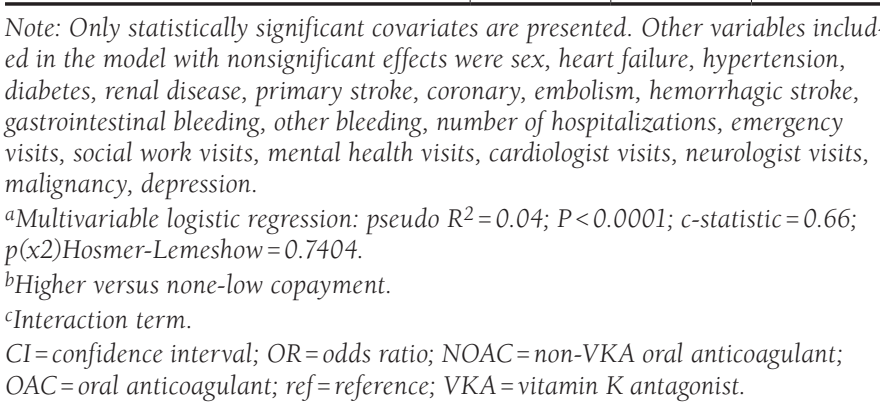 } \\
\hline
\end{tabular}

\section{Factors Correlated to Primary Nonadherence}

In the multivariable analysis, which included adjustment by a propensity score (Table 3), one of the most important predictors of primary nonadherence was the type of anticoagulant, with patients prescribed NOACs showing higher odds of not filling their first prescriptions compared with those prescribed VKAs (OR=2.76; 95\% CI=2.41-3.15). Other factors associated to primary nonadherence were being a foreigner, specifically a non-Spanish European (OR=1.49, 95\% CI =1.12-1.99), and having a diagnosis of dementia $(\mathrm{OR}=1.72,95 \% \mathrm{CI}=1.37-2.16)$. High coinsurance was associated with higher odds of primary nonadherence in the older age groups: $66-75$ years $(\mathrm{OR}=2.63,95 \%$ $\mathrm{CI}=1.47-4.69)$ and $>75$ years $(\mathrm{OR}=3.02,95 \% \mathrm{CI}=1.58-5.76)$.

Prescriptions transmitted electronically to the pharmacy had lower odds of being unfilled than those that were printed $(\mathrm{OR}=0.85,95 \% \mathrm{CI}=0.74-0.96)$. The presence of liver disease $(\mathrm{OR}=0.73,95 \% \mathrm{CI}=0.54-0.99)$ and polypharmacy $(\mathrm{OR}=0.62$, $95 \% \mathrm{CI}=0.53-0.73)$ were also inversely associated with primary nonadherence. Although relevant factors were identified, the predictive capacity of the model was low (c-statistic $=0.66)$.

\section{Discussion}

To our knowledge, this population-based study is the first to describe rates of OAC primary nonadherence in patients with $\mathrm{AF}$ in a real-world setting. The rate of primary nonadherence for OACs among patients with AF was above 5\%, with NOAC initiators nearly tripling the rate of nonadherence compared with VKA initiators. Important differences between NOAC drugs were also identified, ranging from $5 \%$ for apixaban to a percentage as high as $16 \%$ for rivaroxaban. After multivariable adjusted analysis, the type of OAC was one of the strongest predictors of primary nonadherence, with almost 3-fold higher odds for NOACs compared with VKAs. Similarly, patients with high coinsurance in the 2 older age groups were about 3 times more likely to be nonadherent compared with the youngest patients. Other factors related to primary nonadherence included being non-Spanish European; having dementia, liver disease, and polypharmacy; and the transmission method of the electronic prescriptions (printed vs. electronic).

Because of the absence of previous studies, it is not possible to compare this study's findings regarding OAC primary nonadherence rates in routine clinical practice with any other studies. However, primary nonadherence among patients who were newly prescribed OACs was relatively low (5.6\%) when compared with rates observed in some, ${ }^{20,23,24}$ but not all, ${ }^{22,25}$ studies assessing primary nonadherence to other chronic medications, in which primary nonadherence ranged from 3.3\% to 30\%.

Nevertheless, the rate of failure to fill the initial prescriptions continues to be important because of the potential clinical consequences. Primary nonadherence for other medications has been associated with a high risk of subsequent adverse health outcomes. ${ }^{21}$ This study's findings that $5 \%$ of patients with AF did not initiate OAC treatment overall and, importantly, that $11 \%$ of NOAC patients did not fill their first prescriptions are worrisome. Oversight of OAC therapy for even a small fraction of the population (which in absolute numbers is not inconsequential in our population) could have devastating consequences. ${ }^{34}$ Furthermore, the variation according to the drug prescribed, with primary nonadherence rates as high as $16 \%$ for rivaroxaban, deserves attention. These findings imply that the effectiveness of OAC therapy in real-world settings might be limited.

The adjusted analyses confirmed differences in primary adherence by type of OAC, with NOAC patients nearly tripling the odds of primary nonadherence compared with VKA patients. This unexpected finding was robust, despite taking into account several potential confounders and after having adjusted for a propensity score to minimize confounding by indication. Nevertheless, propensity scores attempt to balance in the distribution of observed covariates, which is not necessarily the case with unmeasured confounders. ${ }^{33,35}$ 
We hypothesized that physicians have prescribed NOACs (e.g., rivaroxaban, the only NOAC with a once-daily regime)which are expected to result in better adherence patterns ${ }^{36,37}$ to patients regarded as potentially nonadherent because of characteristics not measured in this study. It has been acknowledged that anticoagulant treatment choices are largely driven by unobserved factors. ${ }^{38}$ If physicians are prescribing NOACs (or a particular drug such as rivaroxaban) in order to ensure better adherence to treatment, it is clear from our findings that additional strategies should be used to improve therapy adherence, and importantly at its starting point, by filling the first prescription.

A previous study assessing secondary adherence among different NOAC users found no difference between rivaroxaban and apixaban adherence rates,$^{38}$ which suggests that once-daily regimes might not necessarily guarantee better adherence compared with twice-daily regimes. An alternative explanation is that given that patients on VKA therapy are closely monitored, those prescribed VKA are more prone to fill the first prescription compared with NOAC patients, since the VKA patients might be aware of the pending international normalized ratio checks. This potential observer effect, however, would not explain the differences between NOAC drugs, so it is unlikely to be the main factor driving these differences in primary nonadherence rates.

Other predictors of primary nonadherence were high coinsurance (only in the 2 older groups), being non-Spanish European, and having a diagnosis of dementia. Previous studies on primary adherence for diverse drugs also found that coinsurance was related to higher primary nonadherence. 22,26 Solid evidence has shown that copayment is a barrier to medication adherence overall. ${ }^{39}$ We are not aware of any study on primary adherence assessing its relationship with native/foreign status. However, a study on asthma medication found that minority groups were more likely to be nonadherent compared with white patients. ${ }^{40}$

Patients with prescriptions electronically delivered to the pharmacy, liver disease, and polypharmacy had lower odds of primary nonadherence. The electronic transmission of prescriptions to pharmacies was found to be inversely related to primary nonadherence in studies assessing medications prescribed for other chronic conditions. ${ }^{23,28}$ Our finding that polypharmacy was related to lower odds of primary nonadherence, although uncommon, has been previously described in a study assessing gaps in first prescriptions for various medications. ${ }^{23}$

Adherence assessment based on data from pharmacy electronic records is a reliable means of determining prescriptions dispensed. This method has an important advantage over other studies using data from electronic medical records, since these studies used pharmacy claims data with no information about physician prescriptions, so they were not able to distinguish a physician's failure to prescribe a medication from a patient's failure to fill a prescription. Studies evaluating the correlation between adherence rates obtained by pharmacy claims and pill counts show a high degree of agreement, ${ }^{41,42}$ so patients who have been dispensed the medication can be considered primary adherent with a relatively high degree of accuracy.

\section{Limitations}

Some limitations to this study must be acknowledged. Information biases because of absent registration or differing data recording practices in the EMR might exist, but this is an inherent problem in any study using data from routine clinical practice. Furthermore, we excluded patients who did not receive their first prescriptions electronically (15\% of initial prescriptions were manual) because that would skew primary nonadherence rates by overestimating the figures. We expected to underestimate the real rates of primary nonadherence because, after electronic prescription has been established in a setting, the percentage of unfilled prescriptions was higher for those issued manually compared with those issued electronically. ${ }^{43,44}$

Although relevant factors associated with primary nonadherence were identified, the predictive capacity of the model was low (c-statistic $=0.66$ ). This might be because some important factors related to adherence (e.g., factors related to healthy behaviors, caregivers, or even health providers) may have not been considered in our study, which is a common issue when working with clinical data from administrative or electronic health records.

Finally, given that this study was observational and based on retrospective real-world data, we can expect the presence of indication bias. We addressed this problem by adjusting for the propensity of being prescribed NOAC therapy. Nevertheless, it must be acknowledged that reverse causation cannot be ruled out, even with propensity score adjustment.

\section{Conclusions}

Primary nonadherence in real-world practice among patients newly prescribed OACs was relatively low overall but high for some specific drugs, which is an important finding because of its potential clinical consequences. Important differences were found by type of OAC, with NOAC-prescribed patients more than doubling the rates of nonadherence compared with those patients prescribed VKAs. However, NOAC primary nonadherence rates were probably driven by the higher rates of rivaroxaban. In the adjusted analysis, NOAC patients nearly tripled the odds of nonadherence compared with VKA patients. This finding highlights the need to explore strategies to improve therapy adherence at initiation and calls on physicians and managed care organizations to consider the present findings when deciding what type of OAC and what specific OAC drug should be prescribed to naive patients. Further study is needed to assess if these findings are replicable in other settings. Other factors related to primary nonadherence were similar to those 
found in studies performed for other medications and can also be used to implement interventions that help patients adhere to therapy from treatment initiation.

\section{Authors}

CLARA L. RODRIGUEZ-BERNAL, PhD; SALVADOR PEIRÓ, PhD; ISABEL HURTADO, PhD; and GABRIEL SANFÉLIXGIMENO, PhD, Health Services Research Unit, Fundación para el Fomento de la Investigación Sanitaria y Biomédica de la Comunidad Valenciana (FISABIO) and Red de Investigación en Servicios de Salud en Enfermedades Crónicas (REDISSEC), Valencia, Spain. ANÍBAL GARCIIA-SEMPERE, MSc, Health Services Research Unit, Fundación para el Fomento de la Investigación Sanitaria y Biomédica de la Comunidad Valenciana (FISABIO), Valencia, Spain.

AUTHOR CORRESPONDENCE: Clara L. Rodríguez-Bernal, PhD, Health Services Research Unit, FISABIO, Avenida Cataluñ 21, 46020 Valencia, Spain. Tel.: 961 925971; E-mail: rodriguez_claber@gva.es.

\section{DISCLOSURES}

This work was partially supported by the 2013 Collaboration Agreement between the Fundación para el Fomento de la Investigación Sanitaria y Biomédica (FISABIO) from the Valencia Ministry of Health and Boehringer Ingelheim, a nonconditioned program to conduct independent research in chronic health care, pharmacoepidemiology, and medical practice variation. Rodriguez-Bernal was funded by the Instituto de Salud Carlos III, Spanish Ministry of Health, and cofinanced by the European Regional Development Fund (grant number RD12/0001/0005). The views presented here are those of the authors and not necessarily those of the FISABIO Foundation, the Valencia Ministry of Health, or the study sponsors. The funding sources had no access to study data and did not participate in any way in the design or conduct of the study, data analysis, decisions regarding the dissemination of findings, the development of the manuscript, or its publication.

Peiró has received fees for participation in scientific meetings and courses sponsored by Novartis and Ferrer International. In 2014, Sanfélix-Gimeno participated in an advisory meeting of Boehringer Ingelheim. García-Sempere is a former employee of Boehringer Ingelheim. Rodriguez-Bernal and Hurtado have no relationships relevant to the contents of this article to disclose.

This work was previously submitted as an abstract (podium presentation) at the 31st International Society of Pharmacoepidemiology (ISPE) Annual Conference; August 22-26, 2015; Boston, Massachusetts.

\section{REFERENCES}

1. Ho PM, Rumsfeld JS, Masoudi FA, et al. Effect of medication nonadherence on hospitalization and mortality among patients with diabetes mellitus. Arch Intern Med. 2006;166(17):1836-41.

2. Ho PM, Spertus JA, Masoudi FA, et al. Impact of medication therapy discontinuation on mortality after myocardial infarction. Arch Intern Med. 2006;166(17):1842-47.

3. Sokol MC, McGuigan KA, Verbrugge RR, Epstein RS. Impact of medication adherence on hospitalization risk and healthcare cost. Med Care. 2005;43(6):521-30.

4. Petersen P, Boysen G, Godtfredsen J, Andersen ED, Andersen B. Placebocontrolled, randomised trial of warfarin and aspirin for prevention of thromboembolic complications in chronic atrial fibrillation. The Copenhagen AFASAK Study. Lancet. 1989(8631);1:175-79.
5. Lancaster TR, Singer DE, Sheehan MA, et al. The impact of long-term warfarin therapy on quality of life. Evidence from a randomized trial. Boston Area Anticoagulation Trial for Atrial Fibrillation Investigators. Arch Intern Med. 1991;151(10):1944-49.

6. Boston Area Anticoagulation Trial for Atrial Fibrillation Investigators, Singer DE, Hughes RA, et al. The effect of low-dose warfarin on the risk of stroke in patients with nonrheumatic atrial fibrillation. N Engl J Med. 1990;323(22):1505-11.

7. Stroke prevention in atrial fibrillation study. Final results. Circulation. 1991;84(2):527-39.

8. Warfarin versus aspirin for prevention of thromboembolism in atrial fibrillation: Stroke Prevention in Atrial Fibrillation II Study. Lancet. 1994;343(8899):687-91.

9. Fuster V, Bhatt DL, Califf RM, et al. Guided antithrombotic therapy: current status and future research direction: report on a national heart, lung and blood institute working group. Circulation. 2012;126(13):1645-62.

10. January CT, Wann LS, Alpert JS, et al. 2014 AHA/ACC/HRS guideline for the management of patients with atrial fibrillation: a report of the American College of Cardiology/American Heart Association Task Force on Practice Guidelines and the Heart Rhythm Society. Circulation. 2014;130(23):e199-267.

11. Connolly SJ, Ezekowitz MD, Yusuf S, et al. Dabigatran versus warfarin in patients with atrial fibrillation. N Engl J Med. 2009;361(12):1139-51.

12. Patel MR, Mahaffey KW, Garg J, et al. Rivaroxaban versus warfarin in nonvalvular atrial fibrillation. N Engl J Med. 2011;365(10):883-91.

13. Granger CB, Alexander JH, McMurray JJ, et al. Apixaban versus warfarin in patients with atrial fibrillation. N Engl J Med. 2011;365(11):981-92.

14. Desai NR, Krumme AA, Schneeweiss S, et al. Patterns of initiation of oral anticoagulants in patients with atrial fibrillation: quality and cost implications. Am J Med. 2014;127(11):1075-82.e1.

15. Rodríguez-Bernal CL, Hurtado I, García-Sempere A, Peiró S, SanfélixGimeno G. Oral anticoagulants initiation in patients with atrial fibrillation real-world data from a population-based cohort. Front Pharmacol. 2017;8:63.

16. Zalesak M, Siu K, Francis K, et al. Higher persistence in newly diagnosed nonvalvular atrial fibrillation patients treated with dabigatran versus warfarin. Circ Cardiovasc Qual Outcomes. 2013;6(5):567-74

17. Schulman S, Shortt B, Robinson M, Eikelboom JW. Adherence to anticoagulant treatment with dabigatran in a real-world setting. J Thromb Haemost. 2013;11(7):1295-99.

18. Yao X, Abraham NS, Alexander GC, et al. Effect of adherence to oral anticoagulants on risk of stroke and major bleeding among patients with atrial fibrillation. J Am Heart Assoc. 2016;5(2):e003074.

19. Zhou M, Chang HY, Segal JB, Alexander GC, Singh S. Adherence to a novel oral anticoagulant among patients with atrial fibrillation. J Manag Care Spec Pharm. 2015;21(11):1054-62. Available at: https://www.jmcp.org/ doi/10.18553/jmcp.2015.21.11.1054.

20. Raebel MA, Carroll NM, Ellis JL, Schroeder EB, Bayliss EA. Importance of including early nonadherence in estimations of medication adherence. Ann Pharmacother. 2011;45(9):1053-60.

21. Jackevicius CA, Li P, Tu JV. Prevalence, predictors, and outcomes of primary nonadherence after acute myocardial infarction. Circulation. 2008;117(8):1028-36.

22. Shrank WH, Choudhry NK, Fischer MA, et al. The epidemiology of prescriptions abandoned at the pharmacy. Ann Intern Med. 2010;153(10):633-40.

23. Cheetham TC, Niu F, Green K, et al. Primary nonadherence to statin medications in a managed care organization. J Manag Care Pharm. 2013;19(5):367-73. Available at: https://www.jmcp.org/doi/10.18553/ jmcp.2013.19.5.367.

24. Derose SF, Green K, Marrett E, et al. Automated outreach to increase primary adherence to cholesterol-lowering medications. JAMA Intern Med. 2013;173(1):38-43. 
25. Fischer MA, Choudhry NK, Bykov K, et al. Pharmacy-based interventions to reduce primary medication nonadherence to cardiovascular medications. Med Care. 2014;52(12):1050-54.

26. Tamblyn R, Eguale T, Huang A, Winslade N, Doran P. The incidence and determinants of primary nonadherence with prescribed medication in primary care: a cohort study. Ann Intern Med. 2014;160(7):441-50.

27. Fischer MA, Stedman MR, Lii J, et al. Primary medication nonadherence: analysis of 195,930 electronic prescriptions. J Gen Intern Med. 2010;25(4):284-90.

28. Fischer MA, Choudhry NK, Brill G, et al. Trouble getting started: predictors of primary medication nonadherence. Am J Med. 2011;124(11):1081.e9-22

29. Sanfélix-Gimeno G, Rodríguez-Bernal CL, Hurtado I, Baixáuli-Pérez C, Librero J, Peiró S. Adherence to oral anticoagulants in patients with atrial fibrillation—a population-based retrospective cohort study linking health information systems in the Valencia region, Spain: a study protocol. BMJ Open. 2015;5:e007613

30. Gage BF, Waterman AD, Shannon W, Boechler M, Rich MW, Radford MJ. Validation of clinical classification schemes for predicting stroke: results from the National Registry of Atrial Fibrillation. JAMA. 2001;285(22):2864-70.

31. Lip GY, Nieuwlaat R, Pisters R, Lane DA, Crijns HJ. Refining clinical risk stratification for predicting stroke and thromboembolism in atrial fibrillation using a novel risk factor-based approach: the Euro Heart Survey on Atrial Fibrillation. Chest. 2010;137(2):263-72.

32. Pisters R, Lane DA, Nieuwlaat R, de Vos CB, Crijns HJ, Lip GY. A novel user-friendly score (HAS-BLED) to assess l-year risk of major bleeding in patients with atrial fibrillation: the Euro Heart Survey. Chest. 2010;138(5):1093-100.

33. Glynn RJ, Schneeweiss S, Stürmer T. Indications for propensity scores and review of their use in pharmacoepidemiology. Basic Clin Pharmacol Toxicol. 2006;98(3):253-59.
34. Hart RG, Pearce LA, Aguilar MI. Meta-analysis: antithrombotic therapy to prevent stroke in patients who have nonvalvular atrial fibrillation. Ann Intern Med. 2007;146(12):857-67.

35. Stürmer T, Rothman KJ, Glynn RJ. Insights into different results from different causal contrasts in the presence of effect-measure modification. Pharmacoepidemiol Drug Saf. 2006;15(10):698-709.

36. Vrijens B, Heidbuchel H. Non-vitamin K antagonist oral anticoagulants: considerations on once- vs. twice-daily regimens and their potential impact on medication adherence. Europace. 2015;17(4):514-23.

37. Andrade JG, Krahn AD, Skanes AC, Purdham D, Ciaccia A, Connors S. Values and preferences of physicians and patients with nonvalvular atrial fibrillation who receive oral anticoagulation therapy for stroke prevention. Can J Cardiol. 2016;32(6):747-53.

38. Brown JD, Shewale AR, Talbert JC. Adherence to rivaroxaban, dabigatran, and apixaban for stroke prevention in incident, treatment-naive nonvalvular atrial fibrillation. J Manag Care Spec Pharm. 2016;22(11):1319-29. Available at: https://www.jmcp.org/doi/10.18553/jmcp.2016.22.11.1319.

39. Choudhry NK, Avorn J, Glynn RJ, et al. Full coverage for preventive medications after myocardial infarction. N Engl J Med. 2011;365(22):2088-97.

40. Wu AC, Butler MG, Li L, et al. Primary adherence to controller medications for asthma is poor. Ann Am Thorac Soc. 2015;12(12):161-66.

41. Steiner JF, Prochazka AV. The assessment of refill compliance using pharmacy records: Methods, validity, and applications. J Clin Epidemiol. 1997;50(1):105-16.

42. Grymonpre R, Cheang M, Fraser M, Metge C, Sitar DS. Validity of a prescription claims database to estimate medication adherence in older persons. Med Care. 2006;44(5):471-77.

43. Adamson AS, Suarez EA, Gorman AR. Association between method of prescribing and primary nonadherence to dermatologic medication in an urban hospital population. JAMA Dermatol. 2017;153(1):49-54.

44. Bergeron AR, Webb JR, Serper M, et al. Impact of electronic prescribing on medication use in ambulatory care. Am J Manag Care. 2013;19(12):1012-17. 


\section{APPENDIX Operational Definitions Used to Determine Patient Comorbidities}

\begin{tabular}{|c|c|}
\hline Comorbidity & ICD-9-CM Definition \\
\hline Congestive heart failure & $428 . x x, 398.91,402.01,402.11,402.91,404.01,404.11,404.03,404.13,404.91,404.93$ \\
\hline Hypertension & 401.xx, 402.xx, 403.xx, 404.xx, 405.xx, 437.2 \\
\hline Diabetes & $250 . x x, 357.2,362.0 x, 366.41$ \\
\hline Liver disease & $\begin{array}{l}571.5,572.0,572.1,572.2,572.3,572.4,572.8,789.5,789.59,570,571.6,571.8,571.9,573.0,573.4,573.8,573.9, \\
782.4,789.1,790.4,790.5,794.8, \mathrm{~V} 42.7\end{array}$ \\
\hline Renal disease & $\begin{array}{l}584.5,584.6,584.7,584.8,584.9,586,585,585.3,585.4,585.5,585.6,585.9,792.5, \text { V42.0, V45.1, V54.11, V45.12, } \\
\text { V56.0, V56.1, V56.2, V56.31, V56.32, V56.8 }\end{array}$ \\
\hline Previous ischemic stroke or TIA & 433.x1, 434.xl, 435.x, 436, 438.x \\
\hline Coronary artery disease & $410 . x x-414 . x x$ \\
\hline $\begin{array}{l}\text { Deep vein thromboembolism or } \\
\text { pulmonary embolism }\end{array}$ & $451.11,451.19,451.2,451.81,451.9,453.40,453.41,453.42,453.5 x, 453.8,453.9,415.1,415.11,415.13,415.19$ \\
\hline Hemorrhagic stroke & 430.xx, 431.xx, 432.x, 852.0x, 852.2x, 852.4x, 853.0x \\
\hline Gastrointestinal bleeding & $\begin{array}{l}455.2,455.5,455.8,456.0,456.20,459.0,530.7,530.82,531.00,531.01,531.20,531.21,531.40,531.41,531.60,531.61, \\
533.00,533.01,533.20,533.21,533.40,533.41,533.61,534.00,534.01,534.20,534.21,534.40,534.41,534.61,535.01, \\
535.11,535.21,535.31,535.41,535.51,535.61,537.83,562.02,562.03,562.12,562.13,568.81,569.3,569.85,578, \\
578.0,578.1,578.9\end{array}$ \\
\hline Other major bleeding & $\begin{array}{l}\text { 423.0, 459.0, 593.81, 719.1, 719.10, 719.11, 719.12, 719.13, 719.14, 719.15, 719.16, 719.17, 719.18, 719.19, 784.7, 784.8, } \\
786.3,599.7,285.1,280.9,280.0,285.9\end{array}$ \\
\hline Bleeding history or predisposition & $\begin{array}{l}\text { 430.xx, 431.xx, 432.x, 852.0x, 852.2x, 852.4x, 853.0x, 455.2, 455.5, 455.8, 456.0, 456.20, 459.0, 530.7, 530.82, 531.00, } \\
531.01,531.20,531.21,531.40,531.41,531.60,531.61,533.00,533.01,533.20,533.21,533.40,533.41,533.61,534.00, \\
534.01,534.20,534.21,534.40,534.41,534.61,535.01,535.11,535.21,535.31,535.41,535.51,535.61,537.83,562.02, \\
562.03,562.12,562.13,568.81,569.3,569.85,578,578.0,578.1,578.9,423.0,459.0,593.81,719.1,719.10,719.11, \\
719.12,719.13,719.14,719.15,719.16,719.17,719.18,719.19,784.7,784.8,786.3,599.7,285.1,280.9,280.0,285.9\end{array}$ \\
\hline Malignancy & $\begin{array}{l}140,141,142,143,144,145,146,147,148,149,150,151,152,153,154,155,156,157,158,159,160,161,162,163, \\
164,165,166,167,168,169,170,171,172,173,174,175,176,177,178,179,180,181,182,183,184,185,186,187, \\
188,189,190,191,192,193,194,195,196,197,198,199,200,201,202,203,204,205,206,207,208,209,210,211, \\
212,213,214,215,216,217,218,219,220,221,222,223,224,225,226,227,228,229,230,231,232,233,234,235 \\
236,237,238,239\end{array}$ \\
\hline Depression & $296.2,296.3,298.0,300.4,301.12,311$ \\
\hline Dementia & $290,294,330,331$ \\
\hline
\end{tabular}

